\title{
INTERVENCIONES SOCIOCOMUNICATIVAS EN LOS TRASTORNOS DEL ESPECTRO AUTISTA DE ALTO FUNCIONAMIENTO
}

\author{
Myriam De La IGLesia ${ }^{1}$ y José-SiXto Olivar ${ }^{2}$ \\ 1 Centro Concertado de Educación Especial «El Corro», Valladolid \\ 2 Facultad de Educación y Trabajo Social, Universidad de Valladolid
}

\begin{abstract}
Resumen: El objetivo de este artículo es presentar una revisión de los estudios e investigaciones sobre los programas de intervención en el ámbito de la comunicación social y más específicamente en el área pragmática en el colectivo de personas con trastornos del espectro autista de nivel alto de funcionamiento cognoscitivo (síndrome de Asperger y autismo de nivel alto). Se analizan algunas propuestas en el área social como los centros de ocio planificado, el trabajo con grupos de iguales, los métodos visuales, las agendas, las «historias sociales» y las «conversaciones en forma de historieta», así como otras propuestas centradas específicamente en los aspectos funcionales y pragmáticos de la comunicación. Se revisan los métodos utilizados y los resultados más significativos obtenidos. Finalmente, se resumen las principales conclusiones de las intervenciones realizadas en el ámbito de la comunicación y relación social.
\end{abstract}

Palabras clave: Trastornos del espectro autista, síndrome de Asperger, relación social, comunicación, habilidades pragmáticas, programas de intervención.

Socio-communicative interventions in high functioning autistic spectrum disorders

\begin{abstract}
The aim of this paper is to present a review of the studies and investigations regarding the programs of interventions in the area of social communication and more specifically in the pragmatic area of people with autistic spectrum disorders (Asperger's syndrome and high functioning autism). Some proposals are analyzed in the social area such as planned leisure centers, working with peer groups, visual methods, agendas, «social stories» and «comic strip conversations», as well as other proposals centered specifically on the functional and pragmatic aspects of communication. The methodology and the most significant results are reviewed. Finally, the principle conclusions of the programs of intervention realized in the area of communication and social relationships are summarized.
\end{abstract}

Keywords: Autistic Spectrum Disorders, Asperger's syndrome, social relationships, communication, pragmatic skills, intervention programs.

\section{INTRODUCCIÓN}

Las dificultades comunicativas más importantes de las personas con trastornos del Espectro autista de nivel alto de funcionamiento cognoscitivo (TEA-AF, en adelante), como el autismo de alto nivel de funcionamiento (AAF, en adelante) y el Síndrome de Asperger (SA, en adelante) comprometen el nivel pragmático del

\section{Recibido 4 mayo 2006; aceptado 28 julio 2006}

Correspondencia: José-Sixto Olivar Parra. Facultad de Educación y Trabajo Social, Universidad de Valladolid, Departamento de Psicología, Campus Miguel Delibes, Paseo de Belén 1, 47011 Valladolid (España). Correo-e: jsolivar@psi.uva.es lenguaje. En concreto, encontramos patrones comunicativos memorizados, perseveración en tópicos específicos, uso de detalles irrelevantes, problemas para seguir frases largas y complejas, en las preguntas que requieren realizar inferencias, las preguntas indirectas que sobrepasan el significado literal, cambios inapropiados de tópicos, dificultades para el inicio o mantenimiento de conversaciones, en el respe-

Agradecimientos: La realización de este trabajo ha sido posible gracias a la Beca de Formación de Personal Investigador (F.P.I.) concedida por la Junta de Castilla y León a la Dra. Myriam De la Iglesia para la realización de la tesis doctoral y a la ayuda de la Consejería de Educación y Cultura de la Junta de Castilla y León al Proyecto VA026/04 dirigido por el Dr. José Sixto Olivar Parra. 
to de los turnos conversacionales, inhabilidad en reconocer las claves y matices sociales, comprensión concreta y literal que no hace uso del conocimiento del contexto semántico y una carencia de estrategias para reparar las conversaciones. Sin embargo, aunque presentan estas dificultades, muestran más habilidades que los otros grupos de personas de menor nivel de funcionamiento cognoscitivo dentro del colectivo de TEA (para una revisión, ver De la Iglesia y Olivar, 2007a).

Los trabajos empíricos de investigación muestran que las dificultades más relevantes del colectivo de personas con TEA-AF tienen que ver con la comunicación y la relación social (Olivar, 2002), por lo que nos centraremos en estas áreas a la hora de analizar los principales programas de intervención.

Habitualmente el área de comunicación y lenguaje se incluye dentro de programas de entrenamiento en habilidades sociales, por lo que primero indicaremos distintas propuestas para el trabajo en el área de la comunicación social (a partir de los centros de ocio planificado, del trabajo con grupos de iguales, y de los métodos visuales, como las agendas, o las «historias sociales» y las «conversaciones en forma de historieta» - Gray, 1998, 2000), y posteriormente recogemos lo referente al trabajo específico en el área pragmática. De la revisión de la literatura en este área podemos concluir que, aunque en la práctica se trabaja en el componente pragmático con este colectivo, existen pocas publicaciones al respecto. Además de escasos, muchos de los estudios e investigaciones carecen de rigurosidad metodológica (p. ej., no indicando las características de la muestra, no evaluando objetivamente los resultados, no incluyendo grupos de control, etc.).

Por lo general, los trabajos en este campo suelen ofrecer principios o técnicas generales más que indicar los contenidos a trabajar. Existen numerosos artículos que ofrecen orientaciones e ideas para la intervención con personas con SA (p. ej., Attwood, 1998; Howlin, 1998; Klin y Volkmar, 2000; Kunce y Mesibov, 1998; Schopler y Mesibov, 1992; Schopler, Mesibov y Kunce, 1998). Sin embargo, no existe un acuerdo significativo en cuanto a los programas que resultan más apropiados para el trabajo con estas personas. Además, en el ámbito de los TEA encontramos demasiada tolerancia hacia tratamientos e intervenciones polémicas y cuyos resultados no han sido empíricamente evaluados y probados (Simpson, 2004). Puesto que la literatura indica que no hay un método que sea más efectivo que los demás, cada vez más, los programas incorporan una variedad de técnicas multidisciplinarias basadas en las necesidades individuales. Así, hay más estudios sobre intervenciones individuales que sobre grupos de entrenamiento (Howlin y Yates, 1999). En muchos de estos trabajos no se incluyen evaluaciones objetivas, ni grupos de comparación, ni muchos de los datos que posibilitarían la valoración objetiva de los resultados presentados.

Por ejemplo, en un estudio de Stoddart (1999) se muestran tres experiencias clínicas a propósito de terapias individuales para problemas psiquiátricos y emocionales de adolescentes con SA ( 2 de 16 años y uno de 13 años) y sus familias, mostrando el estado inicial, los periodos y las orientaciones subyacentes a los tipos de intervención (p. ej., sesiones individuales, discusiones con la familia, etc.), así como los resultados obtenidos. Esto se realiza de manera descriptiva, por lo que carecemos de datos cuantitativos, de la estructuración de las sesiones y de contrastación empírica.

Carrington y Graham (2001) presentan un estudio descriptivo cualitativo sobre dos sujetos con SA de 13 años y sus madres, utilizando entrevistas semiestructuradas. Los temas analizados a través del método inductivo son: el desarrollo evolutivo, los problemas nucleares del SA, los problemas emocionales (estrés y ansiedad), y las situaciones en que los sujetos aparentan ser de una manera y cuando llegan a su casa «explotan» («masquerading»). Incluyen ejemplos de fragmentos de las entrevistas realizadas sobre estos tópicos tanto a los sujetos como a sus madres. Concluyen a propósito de los dos casos en particular, indicando cómo reconducir las obsesiones de uno de los sujetos, sobre el riesgo de depresión en ambos adolescentes por ser conscientes de sus diferencias, y sobre sus dificultades de relación social. 
Puesto que el colectivo de personas con TEA-AF habitualmente se encuentra escolarizado en centros ordinarios, la intervención se suele llevar a cabo a partir de las «Adaptaciones Curriculares Individuales» (ACIs). Para los sujetos de menor funcionamiento cognitivo encontramos algunos trabajos sobre los programas de intervención que se realizan en sus centros educativos específicos.

Jordan y Jones (1999) realizan una revisión de las intervenciones educativas para niños con autismo en Inglaterra y Gales, tanto mediante cuestionarios enviados a los profesionales educativos, como revisando la literatura a partir de las bases de datos más relevantes. En este caso articulan su categorización en: (a) enfoques interactivos, en los que encuentran 6 tipos diferentes de intervención y 6 estudios, (b) enfoques comunicativos, en los que destacan 3 tipos con 10 estudios de investigación, (c) los de integración, en los que encuentran 3 programas preescolares, (d), el programa Teacch, del que encuentran 8 estudios, (e) la terapia «Daily Life» (Boston Higashi School) y (f) los enfoques conductuales estrictos como base y no sólo como técnica de intervención, destacando entre los centros basados en este enfoque el «Young Autism proyect», que parece procurar una mayor generalización de los aprendizajes (Lovaas, Smith y McEachin 1989). Aunque el objetivo fundamental de esta investigación era realizar una comparativa de la efectividad de los distintos enfoques, las autoras concluyen que muchos de los estudios revisados tienen poca consistencia metodológica: escaso número de participantes, carecen de grupos de control, de evaluaciones sistemáticas e independientes, etc., por lo que no pueden ofrecer ninguna valoración en este sentido. En ninguno de los estudios especifican que exista población de alto funcionamiento, puesto que habitualmente se encuentran integrados en centros ordinarios.

Debido a esta escasez de estudios experimentales sobre intervenciones, Jordan (1999) recoge en un trabajo las indicaciones para estimular la realización de 5 posibles estudios de evaluación experimental sobre experiencias educativas puntuales (p. ej., si un profesor desea realizar un cronograma visual para aumentar la autonomía de un alumno en la realización de sus tareas diarias). Señala en primer lugar cómo habría que realizarlas y a continuación cómo evaluarlas e interpretarlas. Además, esta autora también había realizado un intenso trabajo de descripción de distintos programas educativos en términos de objetivos, grupos, costes, participación familiar e implicaciones educativas, con la finalidad fundamental de recoger las intervenciones realizadas en el Reino Unido y así facilitar su comparación y posible selección por las familias de los afectados (Jordan, Jones y Murray, 1998).

Por su parte, Salt, Sellars, Shemilt, Boyd, Coulsdon y McCool (2001) presentan un servicio de intervención temprana intensiva, el «Scottish Centre for Autism preschool treatment programme», cuyo objetivo es la mejora de la comunicación social temprana, así como de las habilidades de interacción social, procurando el desarrollo del juego y de la flexibilidad comportamental. Además, ofrecen apoyo emocional y entrenamiento para que los padres realicen una labor de co-terapeutas. Un año después de iniciarse esta experiencia (Salt, Shemilt, Sellars, Boyd, Coulsdon y McCool., 2002) presentan una evaluación de la eficacia de este programa de intervención mediante la comparación de los resultados de un grupo sometido al tratamiento y otro que no. Los niños del grupo con intervención mostraron mejoras significativas en atención conjunta, interacción social, imitación, habilidades de la vida diaria, habilidades motoras y en conducta adaptativa.

Para sujetos con mayor nivel de funcionamiento, Macleod (1999) muestra uno de los servicios específicos de apoyo para adultos con SA: "The Birmingham community» un año después de su creación. Nos ofrece una descripción general del servicio, así como una valoración cualitativa de la evolución de dos sujetos, de 29 y 30 años, a partir de intervenciones que incluyen, por ejemplo, asistir mensualmente a grupos de discusión con otras personas con SA.

El entrenamiento en comunicación para las personas con autismo suele formar parte de los programas para el desarrollo de habilidades sociales. Por esta razón, a continuación presentamos algunos de los resultados de estudios a propósito de programas para el entrenamiento 
en habilidades sociales que indirectamente trabajan los aspectos comunicativos, para posteriormente dar paso a los que lo realizan de manera específica.

\section{INTERVENCIONES EN EL ÁREA SOCIAL Y COMUNICATIVA}

Las dificultades sociales y de aceptación por los iguales pueden ser el resultado de unas deficientes habilidades pragmáticas, lo que a su vez reduce las oportunidades de aprender y desarrollarlas. La mayoría de los programas de intervención en la conducta social están enfocados a la mejora de una amplia gama de habilidades comunicativas, incluyendo dentro de sus áreas de intervención algunas específicas relacionadas con la comunicación, como iniciar y responder a la interacción, saludar, conversar sobre una variedad de temas, o saber hacer y recibir cumplidos (p. ej., Kamps, Leonard, Vernon, Dugan y Delquadri, 1992). De aquéllas señaladas por Martín Borreguero (2004), destacamos, por un lado, el área de «conversación recíproca», que suele incluir la enseñanza de estrategias de apertura y finalización de conversaciones, habilidades para tomar turnos, para reconducir una conversación confusa, para pedir clarificaciones, para seleccionar tópicos apropiados y para usar e interpretar las conductas no verbales; por otro lado, también resulta de interés el área «uso e interpretación de conductas no verbales de comunicación», que implica la interpretación precisa y adecuada de las claves sociales que permiten realizar inferencias acerca de los valores, motivaciones y estado emocional del interlocutor con respecto al foco de la interacción y, así, modular y adaptar su propio comportamiento en función de esa información (Klin y Volkmar, 2000).

Para sujetos con menor nivel de desarrollo cognoscitivo (p. ej., Koegel y Koegel, 1995 entre otros), se han diseñado programas para la mejora de las habilidades sociales y comunicativas, y en los últimos años también se están elaborando para sujetos con AAF y con SA (Webb, Miller, Pierce, Strawser y Jones, 2004). Las intervenciones plantean entre sus objetivos el entrenamiento en (Klin y Volkmar, 2000): Tra- bajar la conciencia de las reglas pragmáticas convencionales de la conversación (p. ej., selección del tópico conversacional, modos de cambiarlo, etc.), fomentar la «lectura» apropiada de las claves sociales (p. ej., tono emocional, volumen, etc.), y entrenar una conversación ajustada al contexto (p. ej., estilo, ritmo, modulación e inflexión, énfasis, ajuste por proximidad física, ruido ambiental, etc.).

Entre las técnicas más utilizadas en los programas de entrenamiento en habilidades sociales encontramos las de modelado, ensayos conductuales, feed-back (ver Luiselli, Taras y Lennon, 1998), role-playing (ver Marriage, Gordon y Brand., 1995), secuencias gráficas de las situaciones sociales (ver Gray, 1998), scripts sociales -i.e. descripciones explícitas de las secuencias de pasos a realizar en una situación específica - (ver Attwood, 1998) y experiencias en vivo (ver Attwood, 1998; Marriage et al., 1995). Con ellas suelen lograr que las personas con TEA-AF realicen apropiadas interacciones, pongan en práctica habilidades sociales, obtengan feed-back instantáneo, y puedan perfeccionar posteriormente sus habilidades sociales de manera independiente (Arthur, Rotatori y Wahlberg., 2001). Attwood (2000) sugiere además la creación de grupos de amigos por carta, o chats por Internet, como medio para aumentar el círculo de amistades de las personas con SA y así poder poner en práctica las habilidades aprendidas. En la Tabla 1 presentamos algunos ejemplos de estudios sobre intervenciones realizadas en el área social y comunicativa.

A continuación exponemos algunas de las investigaciones llevadas a cabo sobre las intervenciones en el área social y comunicativa según los enfoques/tipos de entrenamiento realizados.

\section{Centros de integración social}

Attwood (2000) ha diseñado una propuesta para la integración social de niños y adolescentes con SA, teniendo en cuenta tanto las dificultades sociales de dicha integración, como las estrategias específicas para la intervención. Plantea la necesidad de que estos sujetos interactúen con grupos de niños con desarrollo normal, el trabajo con materiales relacionados con 
Tabla 1. Ejemplos de estudios sobre intervenciones en el área socio-comunicativa en el colectivo de personas con TEA-AF

\begin{tabular}{|c|c|c|c|c|c|}
\hline Autores & $(\mathrm{N})$ & $\begin{array}{c}\text { Edades } \\
\text { (años) }\end{array}$ & $\begin{array}{l}\text { Tipo de entrenamiento / } \\
\text { área trabajada }\end{array}$ & $\begin{array}{l}\text { Sesiones } \\
\times \text { Semanas }\end{array}$ & Resultados \\
\hline $\begin{array}{l}\text { Howlin y } \\
\text { Yates (1999) }\end{array}$ & $\begin{array}{l}10 \text { con autismo } \\
\text { y con SA }\end{array}$ & $19-44$ & $\begin{array}{l}\text { Sesiones clínicas: Habilidades } \\
\text { conversacionales. }\end{array}$ & 1 año & $\begin{array}{l}\text { Mejoras en algunos } \\
\text { componentes }\end{array}$ \\
\hline $\begin{array}{l}\text { Rajendran y Mit- } \\
\text { chell (2000) }\end{array}$ & $\begin{array}{l}2 \text { con SA } \\
2 \text { con dif. emoc. } \\
\text { y conductuales }\end{array}$ & 23 & $\begin{array}{l}\text { Método visual: «Bubble Dialo- } \\
\text { gue program». (ToM): Entendi- } \\
\text { miento interpersonal }\end{array}$ & $1 \times 6$ & $\begin{array}{l}\text { No mejora } \\
\text { significativa }\end{array}$ \\
\hline $\begin{array}{l}\text { Broderick et al. } \\
(2002)\end{array}$ & $\begin{array}{l}\text { Grupos de } 4 / 5 \\
\text { con SA }\end{array}$ & $12-15$ & $\begin{array}{l}\text { Centros de ocio: Habilidades } \\
\text { sociales }\end{array}$ & $8 \times 6$ & Mejora \\
\hline $\begin{array}{l}\text { Chandler et al. } \\
(2002)\end{array}$ & 10 con autismo & 2 у 3 & $\begin{array}{l}\text { Intervención temprana } \\
\text { (pragmática) }\end{array}$ & 18 meses & $\begin{array}{l}\text { Mejora en interac- } \\
\text { ción social y len- } \\
\text { guaje expresivo }\end{array}$ \\
\hline $\begin{array}{l}\text { Kamps et al. } \\
(2002)\end{array}$ & $\begin{array}{l}5 \text { con autismo y } \\
50 \text { normales }\end{array}$ & 9 y 10 & $\begin{array}{l}\text { Aprendizaje cooperativo y } \\
\text { grupo de habilidades sociales }\end{array}$ & & Mejora \\
\hline $\begin{array}{l}\text { Winterman y } \\
\text { Sapona (2002) }\end{array}$ & 1 con TEA & 9 & Historias sociales: Inclusión. & & Mejora \\
\hline $\begin{array}{l}\text { Barry et al. } \\
(2003)\end{array}$ & 4 con ANA & 6-9 & $\begin{array}{l}\text { Habilidades sociales específicas } \\
\text { y conversaciones }\end{array}$ & 8 ses. & $\begin{array}{l}\text { Tendencia a mejora } \\
\text { en habilidades de } \\
\text { conversación }\end{array}$ \\
\hline $\begin{array}{l}\text { Bledsoe et al. } \\
(2003)\end{array}$ & $\begin{array}{l}1 \text { con SA } \\
\text { y TDAH }\end{array}$ & 13 & $\begin{array}{l}\text { Historias sociales: Relaciones } \\
\text { sociales y conducta }\end{array}$ & 5 días & Mejora \\
\hline $\begin{array}{l}\text { Bosseler y } \\
\text { Massaro (2003) }\end{array}$ & 9 con autismo & $7-12$ & $\begin{array}{l}\text { Enseñanza educativa. «Baldi»: } \\
\text { Vocabulario y gramática. }\end{array}$ & & $\begin{array}{l}\text { Mejora de } \\
\text { vocabulario }\end{array}$ \\
\hline $\begin{array}{l}\text { Hetzroni y } \\
\text { Tannous (2004) }\end{array}$ & 5 con autismo & $8-12$ & $\begin{array}{l}\text { Simulación interactiva: Comu- } \\
\text { nicación funcional }\end{array}$ & & Mejora \\
\hline $\begin{array}{l}\text { Mukaddes et al. } \\
\text { (2004) }\end{array}$ & $\begin{array}{l}10 \text { con autismo } \\
11 \text { con tr. reactivo }\end{array}$ & $\begin{array}{l}2-5 \\
2-6\end{array}$ & $\begin{array}{l}\text { Programa psicoeducativo } \\
\text { (TEACCH) }\end{array}$ & $\begin{array}{l}14 \\
\text { sesiones }\end{array}$ & $\begin{array}{l}\text { Efectivo para } \\
\text { ambos grupos. }\end{array}$ \\
\hline
\end{tabular}

la Teoría de la Mente (ToM), con historias sociales, con conversaciones en forma de historieta, con las emociones, y con la imitación. Incluye además la importancia de la evaluación y entrenamiento en hacer amistades, los grupos de entrenamiento en habilidades sociales, así como la importancia de tener en cuenta el perfil cognitivo del sujeto de cara a diseñar el tipo de intervención.

Basándose en que la adolescencia es un momento propicio para trabajar con las personas con SA habilidades de integración social (p. ej., Howlin y Yates, 1999; Koning y Magill-Evans, 2001; Stoddart, 1999), Broderick, Caswell, Gregory, Marzolini y Wilson (2002) estudiaron los beneficios de dos grupos de entrenamiento en habilidades sociales para adolescentes con SA, de 5 y 4 miembros, con chicos y chicas de entre 12 y 15 años durante 8 sesiones. Los módulos que trabajaron fueron: habilidades conversacionales, contacto ocular, postura corporal, emisión y reconocimiento de lenguaje no verbal, resolución de problemas, saber hacer comentarios de reparación, y técnicas de relajación. Posteriormente, los adolescentes con SA fueron incluidos durante 6 semanas, con la ayuda de un voluntario entrenado, en grupos de ocio con otros jóvenes para que practicaran las habilidades trabajadas. Los autores indican que los resultados, no tratados de forma estadística sino por contraste de porcentajes, muestran una mejora de las habilidades sociales de los participantes.

En la actualidad se están desarrollando programas de intervención desde el campo del ocio y 
tiempo libre (De la Iglesia y Olivar, 2005). Uno de los programas, de actividades socioculturales, se basa en una de las características definitorias del colectivo de personas con SA, y es la presencia de intereses restrictivos, repetitivos y estereotipados (APA, 2002). Se fundamenta en la idea de priorizar una visión positiva de esta habilidad, estimulando los «intereses especiales» de los afectados (intereses muy centrados en un tema que suelen llevar a la especialización de la persona en el mismo). Partiendo de esta característica objetiva y de una filosofia positiva del trabajo con estas personas, se toma la existencia de estas «áreas de interés» como un recurso, pudiendo así estimular algunas otras capacidades más deficitarias en entornos naturales (p. ej., uso del lenguaje en situaciones reales, etc.), buscando la generalización de los aprendizajes conseguidos en ambientes más artificiales. Así, esta característica no constituye una limitación o criterio negativo, sino un importante recurso de cara al trabajo con este tipo de discapacidad (De la Iglesia y Olivar, 2006a). Otra propuesta (De la Iglesia y Olivar, 2006b) es la elaboración de un programa de actuación integral, de intervención socioeducativa, que incida favorablemente en la gestión de su tiempo libre. De esta manera, además de enriquecer su tiempo de ocio, se pueden trabajar aquellas habilidades más deficitarias, en contextos naturales en los que puedan poner en práctica los aprendizajes realizados en anteriores actividades y, como consecuencia de todo ello, prevenir la aparición de otros trastornos relacionados (p. ej., ansiedad, depresión y/o trastornos de conducta) y aumentar su calidad de vida, al mejorar de manera global su capacidad de integración social en la comunidad, ofreciendo la información y formación necesaria a aquellos agentes sociales relacionados con la actividad. Algunos de los materiales y actividades realizados en estos grupos de intervención pueden encontrarse, junto con la justificación teórica, en Olivar y De la Iglesia (2007).

\section{Modelado y ayudas para la integración con grupos de iguales}

Muy relacionada con la anterior, existe otra manera eficaz de entrenar las habilidades sociales y comunicativas, que consiste en trabajar con grupos de niños con TEA-AF y sus iguales sin trastornos (para una revisión, ver Barry, Klinger, Lee, Palardy, Gilmore y Bodin, 2003). El procedimiento implica entrenar a niños con desarrollo normal para aplicar estrategias para iniciar interacciones con el niño con discapacidad; reforzar sus conductas sociales y habilidades de juego, alabar sus intentos de participación y resolver posibles conflictos sociales.

La finalidad de este tipo de estrategias es reducir los efectos del aislamiento social. Los «grupos de juego» consisten en unos 5 niños, uno o dos con TEA-AF y dos ó 3 con desarrollo normal, que son reunidos para jugar y socializarse durante sesiones de unos 30 a 60 minutos. Los estudios realizados señalan mejoras en la calidad y frecuencia de juego, frecuencia y duración de núcleos comunes de actividades, así como en la complejidad del lenguaje en niños con autismo de niveles educativos superiores a los elementales (ver González-López y Kamps, 1997; Zercher, Hunt, Schuler y Webster, 2001). Este tipo de intervención está basada en la teoría de Vygotsky, que indica que las interacciones sociales juegan un papel crítico en el desarrollo normal (Boucher, 1999).

Se han realizado diversas investigaciones sobre intervenciones en habilidades sociales para niños con autismo que implican el entrenamiento de niños con desarrollo normal como co-terapeutas -i.e. compañeros entrenados de juego- (Barry et al., 2003; Goldstein, Kaczmarek, Pennington y Shafer, 1992; Kunce y Mesibov, 1998; Laushey y Heflin, 2000). Los resultados parecen apoyar el uso de esta técnica por su eficacia en la enseñanza y generalización de comportamientos sociales y habilidades de comunicación, tales como el contacto ocultar, la toma de turnos, estrategias comunicativas para pedir y llamar la atención de otro niño, etc. (Ozonoff, Dawson y McPartland, 2002). Estudios recientes han demostrado que el tipo de instrucción en que un compañero tutoriza a una persona con autismo es más eficaz que los métodos tradicionales, incluso en las actividades académicas (p. ej., para la enseñanza de la lectura), es lo que se viene denominando «Sistema del amigo o 
compinche empático». Además, no sólo mejoran en sus objetivos escolares, sino también en su conducta y habilidades sociales (Fulk y King, 2001).

No obstante, existe poca investigación para determinar el eficacia de este tipo de intervenciones con niños con autismo fuera de la escuela (Rogers, 2000). En general, los resultados de las intervenciones apuntan a que existen mejoras globales de habilidades sociales, aunque no han logrado encontrar evidencia de mejoras en gran escala. Además, con algunas pocas excepciones (ver Laushey y Heflin, 2000), estas interacciones sociales no se generalizan en otros contextos, con pares no entrenados (ver Rogers, 2000, para una revisión). En el mismo sentido, la mayoría de los estudios encuentra que este entrenamiento de iguales se traduce en un importante incremento de las iniciaciones sociales de los niños con desarrollo normal, pero menor en los niños con autismo (Goldstein et al., 1992; Haring, Breen, Pitts-Conway, Lee, y Gaylord-Ross, 1987; Sainato, Goldstein y Strain, 1992).

Zercher et al. (2001) estudiaron a dos hermanos gemelos de 6,3 años con autismo, con 3 hermanas de desarrollo normal de 5,5; 9,6; y 11,9 años. Las condiciones de trabajo eran tres: «sin intervención», «intervención con ayuda del adulto» $\mathrm{y}$ «sin ayuda». Tras el entrenamiento, las 3 niñas con desarrollo normal pusieron en práctica las técnicas de «integración en grupos de juego» 30 minutos semanales durante 16 semanas. Los autores encontraron que la participación en estos grupos produce un aumento de las interacciones con los iguales, consistentes en atención conjunta, habla y juego simbólico, aunque parecía ser menos efectiva para aumentar la atención conjunta hacia las actividades en los sujetos con discapacidad. Las mejoras se mantenían cuando la ayuda del adulto era retirada.

Kamps, Royer, Dugan, Kravits, GonzálezLópez, García, Carnazzo, Morrison y Kane (2002) realizaron una investigación en que concluyen que estos grupos con iguales sin discapacidad son significativamente mejores para el aumento de las interacciones sociales de los niños con autismo, así como para la generalización de los aprendizajes. La investigación con- sistía en dos estudios. En el primero, realizado durante un curso académico, participaron 5 estudiantes con autismo ( 2 niñas y 3 niños) de 9 y 10 años — sólo uno tenía un alto nivel de funcionamiento cognitivo- - y 50 pares (niños y niñas) sin dificultades, de edades similares, distribuidos en 3 grupos de estudio: uno para realizar la experiencia de grupos de aprendizaje cooperativo ( 7 niños y 8 niñas), otro con un grupo de habilidades sociales (11 niños y 5 niñas) y otro como grupo control (10 niños y 9 niñas). Las dos condiciones de intervención muestran mejores resultados en la generalización de los aprendizajes de interacción social. En el segundo estudio, diseñado para evaluar el mantenimiento y generalización de los efectos del grupo de inclusión social durante 3 años, estudiaron a 34 niños con autismo (24 niños y 10 niñas) de entre 7 y 14 años, con un bajo nivel de funcionamiento cognitivo, y cerca de 130 iguales (un $60 \%$ niñas y un $40 \%$ niños) de similar edad o de un año de diferencia (los autores no precisan estos datos). Los resultados indican que existen cambios positivos en las habilidades de interacción de los estudiantes con autismo, y que generalizan estos aprendizajes incluso en los grupos en que los pares no han sido entrenados, siendo mejores cuando están previamente familiarizados con los iguales. Estos resultados positivos son observados tanto en los sujetos con autismo como en los pares sin discapacidad.

Partiendo de la observación de que las intervenciones con este colectivo son muy utilizadas pero habitualmente no son comprobadas empíricamente, el estudio de Barry et al. (2003) aporta una evidencia empírica de la mejora producida. En concreto, fueron entrenadas y evaluadas habilidades sociales específicas en 8 sesiones semanales. La muestra de estudio la componían 4 sujetos con AAF (3 niños y una niña) con edades comprendidas entre los 6 años y 3 meses y los 9 años y 2 meses. En las sesiones 1 y 2 el trabajo se centró en saber iniciar y responder en conversaciones, en las sesiones 3 a 6 en responder a una invitación de juego, y en las sesiones 7 y 8 en pedir a otros que jueguen. Todo esto durante interacciones con niños sin dificultades previamente entrenados (con 4 niños y 3 niñas con una media de edad de 8 
años y dos meses). Las evaluaciones se realizaron a partir de cuestionarios a los padres, observaciones de 5 minutos jugando con los pares con desarrollo normal, mediante entrevistas telefónicas semanales a los padres de $10 \mathrm{minu}-$ tos aproximadamente, y con mediciones pretest y postest a partir de escalas acerca de la conciencia de apoyo social y de soledad de los niños. Así como en las habilidades de saludo y de juego observaron un cambio significativo, los resultados en habilidades de conversación indican sólo una tendencia a la mejora. Además, aunque existen cambios positivos en sus habilidades sociales, esta mejora no se encuentra en la misma medida en cuanto a generalización. Indican que estos resultados pueden deberse bien a que no instruyeron tan específicamente en la habilidad conversacional, o al bajo poder estadístico de los resultados debido al reducido tamaño de la muestra (Barry et al., 2003).

\section{Sistemas visuales}

La información que llega por la vía auditiva es por naturaleza fugaz y debe almacenarse directamente en la memoria siguiendo un esquema secuencial basado en el tiempo. Esto nos permite aclarar posteriormente su significado en función de otras informaciones que nos llegan al mismo tiempo o más tarde. El uso de sistemas visuales de representación del lenguaje va a permitir observar más detenidamente el lenguaje, analizarlo, repasarlo varias veces, comprender su justificación y guardarlo así más fácilmente en la memoria a largo plazo.

Las técnicas de visualización emplean básicamente como recursos el dibujo, que permite la representación estable de situaciones interactivas, emociones, secuencias sociales...; puede usarse también en forma de pictogramas o de esquemas para servir de «andamiaje» para la realización de diferentes comportamientos. Otro medio es el lenguaje escrito, que es con seguridad el sistema aumentativo visual más potente y de mayor uso en el trabajo con estas personas. Permite perseguir los mismos objetivos que el dibujo, pero de una forma mucho más amplia y precisa. Además de con dibujos, también pueden realizarse fotografías que representen actividades habituales (para una revisión, consultar Olivar y De la Iglesia, 2007).

Diversos autores han creado programas de intervención basados en métodos visuales y con una metodología adaptada a este colectivo, como el desarrollado por Sussman (1999) «More Than Words» en el que se recogen un buen número de actividades para ayudar a los padres a mejorar la comunicación y las habilidades sociales de niños con TEA; el «Power cards» de Gagnon (2001), que se basa en usar los intereses especiales para motivar a los niños y adolescentes con SA; o el «Visual Supports» de Savner y Smith (2000), que elabora un sistema de apoyos visuales que los niños con SA pueden utilizar para trabajar tanto en casa como en la comunidad. Sin embargo, sin bien hay una coincidencia casi unánime en los beneficios del empleo de material visual en los TEA, hasta la fecha no se han presentado trabajos empíricos con datos reales sobre su eficacia.

En esta misma línea de intervención, las «agendas personales», utilizadas por ejemplo en el Proyecto PEANA (Tamarit, De Dios, Domínguez y Escribano, 1990) están basadas en la utilización de claves visuales claras para situar a los sujetos en el espacio y en el tiempo. Consisten en elaborar junto al niño carteles y breves «historias anticipatorias con dibujos y viñetas esquemáticos pero detallados y realistas que representan y anticipan cada uno de los acontecimientos que ocurran en la jornada, respondiendo a la pregunta «¿qué voy a hacer?», al tiempo que se escriben y se explican (Ventoso y Osorio, 1997). Las principales finalidades perseguidas son las de lograr previsibilidad, ayudar a dar sentido a la experiencia y a la acción, favorecer el intercambio comunicativo, facilitar los aprendizajes, e incluso trabajar el reconocimiento de caras para mejorar la comprensión socioemocional. Además, estos procedimientos pueden servir para identificar áreas de interés y buenas capacidades que pueden utilizarse para enseñar otras habilidades más deficientes.

Mediante las «agendas personales» se consigue estimular la «experiencia narrativa», siendo denominadas este caso «narraciones anticipatorias» (Rivière, 1997), a la vez que se trabajan conceptos temporales que pueden 
entrañar alguna dificultad (p. ej., «primero-luego»). En las personas con TEA-AF es posible usarlas como claves externas para entrenar también habilidades conversacionales. En los aspectos lingüísticos, según informan Ventoso y Osorio (1997, pp. 584), los cambios producidos observados por diferentes terapeutas y familiares en el contexto de una intervención - no como investigación empírica, sino como una experiencia de trabajo-son:

1. Aparición de nexos de unión temporales (i.e. después, de repente, luego, cuando se acabe...), dando mayor sentido a las frases.

2. Mayor calidad morfosintáctica en las expresiones espontáneas: ordenación más adecuada.

3. Aparición de declarativos, relacionados con los acontecimientos importantes.

Este tipo de métodos visuales también han sido adaptados para su uso a través del ordenador. Así, Rajendran y Mitchell (2000) realizan un estudio con dos jóvenes adultos con SA (de 23,4 y 23,2 años) y otros dos jóvenes atendidos en una escuela para niños con dificultades emocionales y conductuales (de 14,9 y 14,10 años). En un estudio anterior y que sirve de base a éste (Hadwin, Baron-Cohen, Howlin y Hill, 1996) los resultados obtenidos eran limitados porque las mejoras no se generalizaron a las áreas no instruidas, probablemente porque los niños «podrían estar aprendiendo a pasar las tareas más que entendiendo los conceptos que son la base de las reglas» (Hadwin et al., 1996, pp. 359). En este caso, la intervención se llevó a cabo con el «Bubble Dialogue Program» (Gray, Creighton, McMahon y Cunningham, 1991). Esta aplicación crea un role-play en forma de historieta dibujada, en la que cada uno de los dos usuarios debe interpretar un rol. Mediante el uso de distintos iconos pueden insertar texto en un bocadillo similar al de un cómic, que puede ser sustituido posteriormente por el texto que recrea su pensamiento. El procedimiento de representar los estados mentales de esta manera ha demostrado ser efectivo con personas con AAF-SA (para una revisión, ver Wellman, Baron-Cohen, Caswell, Gómez, Swettenham, Toye y Lagattuta, 2002).
Así, mientras el programa regula la toma de turnos y sirve como un interfaz entre los dos usuarios, éstos tienen acceso tanto al discurso como a los pensamientos del otro, siendo literalmente capaces de «leer las mentes». Las sesiones de trabajo fueron de una hora por semana durante 6 semanas. Los materiales para este estudio fueron 6 guiones inspirados en las tareas de ToM. Aunque los resultados muestran que no existe una mejora significativa antes y después de las sesiones en el entendimiento interpersonal de los participantes con SA, sí existe una mejora significativa en sus funciones ejecutivas, pues estas tareas requieren flexibilidad de pensamiento y acción, así como planificación del transcurso del diálogo. Los autores hipotetizan que puede que por esta razón mejoraran las funciones ejecutivas, y que éstas precedan a los cambios en la capacidad verbal. Además, aunque el tamaño de la muestra es reducido, puesto que los sujetos con SA no mostraron comportamientos significativamente diferentes a los de los participantes con dificultades emocionales y conductuales en las situaciones con más carga emocional, proponen que la comunicación por correo electrónico, por Internet, así como las situaciones de realidad virtual, puede ayudar a las personas con SA con las dificultades en las interacciones sociales.

Otros estudios han utilizado esta misma metodología visual para el entrenamiento en tareas de Teoría de la Mente (ToM). Wellman et al. (2002) presentan dos trabajos, uno con 7 sujetos, todos varones, de entre 8 y 18 años $(M=11,2)$ y de una media de 5,6 años de edad mental, y otro con 10 sujetos, 9 niños y una niña de entre 5 y 17 años $(M=11,2)$ y una media de 4,11 de edad mental. El objetivo era ayudar a resolver tareas de ToM representando gráficamente los estados mentales de los personajes y entrenando en tareas de falsa creencia. En el primer estudio, tras entrenar durante 5 sesiones de aproximadamente 30 minutos por día, obtuvieron evidencia de la eficacia del método utilizado, pues mejoraron la realización de tareas de falsa creencia incluso en la fase de evaluación en que no incluyeron los «bocadillos con los pensamientos». En el segundo, también con 5 sesiones de aproximadamente 30 minutos por día de entrenamiento, obtuvieron 
que el aprendizaje se mantenía en las evaluaciones de postest, transfer cercano y lejano.

Sin embargo, y aunque existe evidencia a favor del trabajo con ordenadores para el aprendizaje de las personas con TEA-AF, aún no existen muchos estudios en este área (Rajendran y Mitchell, 2000).

Otros procedimientos muy interesantes que utilizan el soporte visual son las «Social stories» o «Historias sociales», desarrolladas por Carol Grey. Son cuentos cortos que describen objetivamente a personas, lugares, acontecimientos y conceptos o situaciones sociales, siguiendo un contenido y formato específico (Gray, 1998). Las historias pueden estar escritas por el niño, por el adulto o por los dos. Normalmente se escriben en primera persona y en presente. Esto personaliza el contenido y evita problemas con la percepción del tiempo y con la sintaxis. El vocabulario de la historia social debe ser apropiado a la edad, a la comprensión de lectura y al nivel de atención del niño (Gray, 1998). La historia para un niño de preescolar contendrá pocas palabras y claras, e incluirá fotos e ilustraciones. Los pre-lectores pueden escuchar la historia en una cinta de audio. Los padres y profesores de los niños mayores pueden preparar la historia como si fueran periodistas, usando lenguaje y gráficos periodísticos. Por ejemplo, se puede escribir un artículo sobre los códigos de conducta entre amigos o sobre qué hacer y decir al encontrarse con un compañero de clase mientras se está de compras con la familia.

Han de incluir los elementos más importantes de la situación social, incluyendo: quién, qué, cuándo, dónde y por qué. Tienen como características más relevantes (Gray, 1998): a) Que se realizan desde la perspectiva del alumno; b) Que su objetivo es proporcionar información social precisa; c) Que los materiales, técnicas y métodos se utilizan en función de las características del aprendizaje del alumno; y d) Que son individualizadas e incorporan necesidades y habilidades individuales, así como preferencias e intereses para aumentar la comprensión del entorno social.

La escritura de la historia se realiza de acuerdo a unas directrices específicas basadas en el uso de esta técnica por su creadora Carol Gray.
Esta técnica sirve para dirigir la escritura de niños o adolescentes con dificultades con la lengua expresiva, sobre todo aquéllos con TEA, y está demostrando ser notablemente efectiva para hacer que las personas con AAF-SA entiendan las señales y acciones en determinadas situaciones sociales. Ayudan a estimular lo que Attwood denomina «sentido común social» (Attwood, 1998).

El formato de las historias sociales consiste en cuatro tipos de oraciones básicas escritas en una proporción específica respecto al total de la historia, a saber: descriptiva: define objetivamente dónde ocurre una acción, quién está involucrado, qué están haciendo y por qué; de perspectiva: describe y explica, si es necesario, las reacciones y sentimientos de los demás en una situación dada; directiva: enuncia lo que se espera que el niño diga o haga; de control: desarrolla estrategias para ayudar a que la persona recuerde lo que debe hacer o cómo entender la situación. Es importante que haya un equilibrio de estos cuatro tipos de frases, intentando evitar demasiadas frases directivas y demasiadas pocas frases de perspectiva y descriptivas. Gray acentúa la importancia del proceso de escribir correctamente las oraciones, que considera más importante que el producto, pues debe reflejar la perspectiva de la persona a quien se dirige, y recomienda una razón de 0 1 frases directivas y/o de control por cada 2-5 frases descriptivas y/o de perspectiva.

Actualmente, las historias sociales están creciendo en popularidad y reconocimiento (Rogers y Myles, 2001), realizándose con ellas intervenciones para la mejora de la comunicación de niños con TEA (Adams, Gouvousis, Van Lue y Waldron, 2004). Aún así, la investigación objetiva sobre los resultados de la intervención con estos métodos está aún por determinar. Por otra parte, no sólo se utilizan para trabajar aspectos comunicativos. Así, por ejemplo Swaggart, Gagnon, Bock, Earles, Quinn, Myles y Simpson (1995) combinan el uso de las historias sociales con el tradicional entrenamiento conductista para el entrenamiento en habilidades sociales con 3 niños con autismo de nivel medio y bajo de funcionamiento cognitivo (7 a 11 años). El primero solía responder mediante agresiones físicas a los cambios 
en las rutinas, el segundo prefería el juego solitario ignorando al resto, y el tercero tenía unas interacciones sociales basadas en el contacto físico abrupto. Los autores informan de los resultados positivos para la enseñanza de nuevas habilidades y la disminución de conductas disruptivas (Swaggart et al., 1995); sin embargo, con esta intervención no podemos saber sólo el impacto relativo de las historias sociales (Gray, 1998). En el mismo área de trabajo conductual, Kuttler, Myles y Carlson (1998) obtuvieron buenos resultados a propósito del efecto de las historias sociales en reducir los precursores de las rabietas de un niño con autismo de 12 años. Incluso se han trabajado con éxito historias sociales a partir de un formato multimedia con 3 niños con autismo con una edad de educación elementaria para el aprendizaje de nuevas conductas (para una revisión, ver Bakken y Bock, 2001).

Winterman y Sapona (2002) describen el tipo de intervención educativa realizada con un niño con TEA de 9 años, desde el enfoque de «aula responsiva/sensible», dentro de un contexto de inclusión. Entre las técnicas utilizadas incluyen las historias sociales y la participación de un igual. Aunque no muestran una valoración formal del cambio, concluyen una mejora del alumno en su inclusión en el aula y en la participación en las actividades (i.e. en una actuación musical).

Basándose en que las historias sociales pueden ayudar a comprender y utilizar adecuadamente normas de protocolo social (Gray, 1998), Bledsoe, Smith y Simpson (2003) realizan un estudio acerca de una intervención haciendo uso de historias sociales para modificar ciertas conductas que entorpecían la aceptación social y las relaciones con sus iguales durante la comida en un adolescente de 13 años con diagnóstico de SA y Trastorno por déficit de atención e hiperactividad. Las conductas objetivo eran dos: trataban de disminuir la tendencia a derramar la comida, y de estimular que estuviera con la boca limpia. El total del estudio comprende 21 días, y durante 5 trabajaron la historia social antes de comer. Los resultados indican que esta intervención es un medio adecuado para trabajar la conducta y dificultades sociales de las personas con TEA, aunque los autores añaden que es preciso realizar más investigaciones para determinar la importancia del sexo, edad, características cognitivas y lingüísticas, motivación para el cambio, habilidades de interacción social, etc. (Bledsoe et al., 2003).

En la misma línea que las anteriores historias sociales, Carol Gray (1998) ha diseñado las «comic strip conversations» $\mathrm{o}$ 《conversaciones en forma de historieta». Son un tipo de intervención fundamentado en el uso de estrategias de apoyo positivas conductuales, que ayudan al trabajo con habilidades sociales, mentalistas y comunicativas (González-Carvajal, 2002). Esta estrategia dota de apoyos explícitos a las personas con dificultades de comunicación para las que el uso del lenguaje oral para comunicarse con sus pares supone un esfuerzo. Además, son un recurso que viene demostrando gran eficacia en la educación de las personas con autismo (González-Carvajal, 2002), pues sirven como ayuda adicional en la comprensión del rápido intercambio comunicativo de información presente en cualquier conversación oral (Rogers y Myles, 2001).

Mediante el empleo de dibujos simples con figuras de palo (pictogramas), símbolos gráficos y color, que identifican la situación, las ideas y los conceptos abstractos, sirven para facilitar la interacción visual entre dos o más personas. A través del uso de «bocadillos» similares a los de los cómics se representa qué dice, siente, cree, hace y piensa cada persona en una situación particular. Con su uso se pretende favorecer que las personas con AAF-SA actúen de manera más positiva y recíproca con sus compañeros, estimulando el uso de la lengua y conversación, aumentando el entendimiento social (Rogers y Myles, 2001), la predictibilidad y la organización, pues se informa al sujeto sobre lo que sucede en una situación dada y porqué (Gray, 1998). Además, ayudan a los padres y profesionales a entender la perspectiva de la persona con AAF-SA, y estimulan una mejora del comportamiento disruptivo (Rogers y Myles, 2001; Rowe, 1999).

La motivación y los sentimientos subyacentes a las declaraciones (los aspectos ocultos de la comunicación), se pueden identificar mediante el uso de colores en las conversacio- 
nes. De esta manera podemos trabajar un modelo de respuesta, por ejemplo ante comentarios cuya intencionalidad no es transparente (chistes, ironías, etc.). Una de las mayores ventajas del uso de las conversaciones en forma de historieta es que aprovecha uno de los puntos fuertes de este colectivo, como es la comprensión de la información presentada gráficamente, permitiendo visualizar tanto la acción y situación que se desarrolla, como el intercambio comunicativo (Gray, 1998; Rogers y Myles, 2001). Además, al mostrar la interacción comunicativa de manera visual, el sujeto puede «ver»" la conversación, y así tener más control sobre ella (Gray, 1998).

Se han utilizado las conversaciones en forma de historietas para diversos propósitos. Así, Glaeser, Pierson y Fritschmann (2003) presentan un trabajo descriptivo sobre el proceso de introducir esta metodología en el aula, y cómo fueron observando cualitativamente (no empíricamente) una disminución de las conductas disruptivas. Uno de los dos sujetos de estudio era una niña con AAF. Describen el uso de las conversaciones en forma de historieta en tres fases (paso 1: introducción y modelado, paso 2: creación de un diccionario de símbolos y paso 3: reforzar su uso). Los autores concluyen que los dos niños con los que intervinieron comenzaron a ganar confianza en su capacidad de poner sus sentimientos, pensamientos, o ideas en palabras, además de realizarlo cada vez más independientemente.

\section{INTERVENCIONES CENTRADAS ESPECÍFICAMENTE EN EL ÁREA PRAGMÁTICA}

Las intervenciones en comunicación y lenguaje con personas con AAF-SA suelen centrarse en los aspectos pragmáticos y funcionales de la comunicación. Algunas investigaciones han demostrado la efectividad de procedimientos y programas diseñados para la intervención en este área, por ejemplo, para aumentar el uso de preguntas para iniciar la interacción (i.e. Koegel, Camarata, ValdezMenchaca y Koegel, 1998) u otras iniciaciones verbales espontáneas (i.e., Koegel, Koegel, Shoshan y McNerney, 1999).

Las intervenciones para mejorar la comunicación se han estructurado en torno a las siguientes áreas (Koegel, 2000): a) Aumento de la espontaneidad, de las iniciaciones, y la variedad de las funciones lingüísticas de niños verbales y no verbales, b) Evaluaciones e intervenciones tempranas con resultado positivo, c) La participación de las familias en los programas de la intervención; d) Buenas prácticas para las intervenciones comunicativas; e) La relación entre el lenguaje y otros síntomas conductuales; y f) El empleo social y pragmático del lenguaje. Aunque los trabajos de intervención en contextos estructurados suelen mostrar resultados positivos, habitualmente fallan en demostrar la generalización de los aprendizajes en otros contextos.

Los programas de tratamiento para niños con TEA-AF suelen realizarse durante cortos periodos de tiempo, varios días a la semana. Por ejemplo, Kamps y su equipo (Kamps et al., 1992) enseñaron habilidades a niños de primer grado en periodos de 10 minutos 4 días a la semana. Como manifiestan Barry et al. (2003), lo ideal sería poder realizar estos entrenamientos en el contexto escolar 5 días o más a la semana, durante un periodo o más al día. Pero esto no es posible en el contexto de la intervención clínica, donde las sesiones suelen ser semanales y de una media de 50 minutos, con lo que proponen el contexto escolar para garantizar la generalización de los aprendizajes realizados en contextos artificiales y controlados.

Bakken y Bock (2001) realizan un trabajo en que categorizan las intervenciones para las habilidades comunicativas según la metodología utilizada (p. ej., las realizadas en contextos naturales y las que se llevan a cabo en un contexto estructurado) con personas con autismo. Los autores sólo refieren el colectivo con un nivel alto de funcionamiento a propósito de una de las intervenciones de tipo estructurado para la mejora del lenguaje semántico-pragmático. En concreto, informan de que Ogletree, Fischer y Sprouse (1995, cit. en Bakken y Bock, 2001) utilizaron un programa de tratamiento diseñado para facilitar el lenguaje semántico y pragmático en una mujer con AAF. Recurriendo a 
secuencias de vídeo basadas en sus intereses especiales (i.e. viñetas con dibujos de Disney), realizaron role-play de cada secuencia, trabajando posteriormente las habilidades mostradas. Los resultados mostraron un incremento en contacto ocular correcto, respuestas en un tiempo apropiado y un adecuado mantenimiento del tópico conversacional.

Para comprobar la eficacia de los procedimientos de aprendizaje utilizados, Delprato (2001) examina una serie de estudios según estén realizados mediante el procedimiento tradicional operante o con procedimientos naturales. El objetivo era conocer cuáles cumplían los prerrequisitos de investigaciones experimentales. De los 10 estudios que cumplen este criterio de inclusión llama la atención que sólo la mitad evalúan la generalización de los aprendizajes.

Con este mismo propósito, Howlin y Yates (1999) realizan un estudio basado en la idea de que existe poca información sobre las estrategias que se utilizan en los grupos de entrenamiento, así como sobre la efectividad de la intervención. Con un grupo de diez participantes masculinos con AAF o con SA de entre 19 a 44 años $(M=28,4)$ plantean un programa de entrenamiento en habilidades sociales que hace especial hincapié en el trabajo de las habilidades conversacionales. En concreto, en este área, se centran en las maneras de iniciar y mantener conversaciones, las maneras apropiadas de responder, y en la necesidad de evitar las expresiones repetitivas y estereotipadas. Este entrenamiento se lleva a cabo mediante reuniones mensuales de cerca de dos horas y media, utilizando como estrategias el role-play, actividades de equipo y juegos estructurados, e incorporando feedback mediante grabaciones en video realizadas durante las sesiones. Tras el primer año de intervención se pregunta a las familias y a los componentes del grupo acerca de los progresos observados. Para objetivar los datos, se comparan grabaciones de los estilos conversacionales de los participantes antes y después de la intervención. Aunque observan mejoras en el porcentaje de inicios y mantenimientos de conversaciones y en las repeticiones y comentarios inadecuados, los autores argumentan que la carencia de un grupo de control impide atribuir los cambios exclusivamente a la intervención.
Además, afirman que no pueden valorar el grado de generalización que tendrán sus resultados en contextos no entrenados y más naturales.

Un trabajo de investigación que incide de manera más precisa en los aspectos pragmáticos del lenguaje, es el desarrollado por Chandler, Christie, Newson y Prevezer (2002). En él plantean una intervención temprana basada en que la pragmática es la precursora del lenguaje y facilita tanto la comunicación como las relaciones entre el niño y los padres. Diez niños con autismo de entre 1,10 y 2,9 años al inicio de la investigación, y de 3,5 a 4,6 al final de la misma, fueron evaluados y objeto de una intervención individualizada durante 18 meses. El programa de intervención incluía visitas a los hogares, modelado, y talleres e información diaria por medio de notas, con los padres como co-terapeutas. Los programas incluían las siguientes áreas: lenguaje expresivo (verbal y no verbal), lenguaje receptivo y juego recíproco. Los resultados fueron positivos tanto para los padres como para los niños en interacción social y lenguaje expresivo, aunque son presentados de manera cualitativa (p. ej., ejemplos de respuestas a los cuestionarios administrados a los padres, etc.).

También se han incorporado los sistemas informáticos para la intervención de los aspectos pragmáticos de la comunicación. Attwood (2000) recomienda que para mejorar sus habilidades sociales y comunicativas, estos sujetos pueden recurrir a hacer grupos de amigos por carta, clubs, chats y foros en Internet sobre sus intereses especiales, etc. Algunas de las ventajas más destacables de la comunicación interactiva en foros y chats son el rápido encuentro con un interlocutor dispuesto a mantener una conversación, la disminución de la ansiedad que puede suponer un encuentro físico, o la posible mediación de un adulto que pueda ir aconsejando y entrenando al sujeto. Al mismo tiempo, se va desarrollando una conversación con un interlocutor real de una manera gradual, secuenciada y motivante. Además, el respeto de los turnos de habla, intercambiando el rol de emisor y receptor conforme va teniendo lugar la comunicación se representa gráficamente (i.e. la persona con AAF-SA podrá ir observando cada una de las intervenciones de su interlocutor, teniendo tiempo para preparar una posible respuesta, 
o para consultar al adulto las posibles dudas que le surjan antes de responder). Por otra parte, los ordenadores son un recurso altamente motivante para las personas con AAF-SA.

En este sentido, Bosseler y Massaro (2003) estudiaron la efectividad de una intervención dirigida al aprendizaje de vocabulario y gramática en dos escuelas para niños con autismo. El entrenamiento lo realizaron mediante un sistema informático denominado «Baldi», que es un programa que representa un rostro que enseña vocabulario y gramática como si fuera un interlocutor real. Además, los autores valoraron si el aprendizaje se mantenía 30 días después de la intervención. La muestra de estudio la componían 9 niños con autismo (una niña y 8 niños), de edades comprendidas entre los 7 y los 12 años. La evaluación indicó que los niños aprendieron el vocabulario, y que fueron capaces de recordar el $85 \%$ del mismo 30 días después de su enseñanza. Tras un nuevo entrenamiento, evaluaron su generalización a imágenes nuevas, sin la presencia del ordenador, con una persona distinta al entrenador, en 6 de los participantes. Tras las sesiones de entrenamiento, todos mostraron un aumento de vocabulario y una generalización del vocabulario aprendido.

Hetzroni y Tannous (2004) realizaron una intervención cuyo objetivo era valorar los efectos del uso de ordenadores para la puesta en práctica de comunicación funcional. Los participantes en la investigación eran 5 niños con autismo (3 niños y 2 niñas) de entre 7,8 y 12,5 años de edad cronológica (no indican la valoración del nivel de funcionamiento cognitivo), con ecolalia funcional demorada. Las variables evaluadas fueron: las ecolalias inmediatas y demoradas, el lenguaje relevante y el irrelevante, así como las iniciaciones de comunicación por los sujetos. Los niños debían practicar actividades simuladas en el ordenador basadas en situaciones familiares (i.e. juego, comida e higiene). Los resultados indican la eficacia de la simulación interactiva de las actividades diarias como medio para aumentar la comunicación adecuada, pues destacan una disminución de las ecolalias demoradas y del lenguaje irrelevante y un aumento del lenguaje apropiado en los 5 sujetos, en las 3 situaciones, así como una mayor comunicación funcional en los 5 sujetos, en las situaciones de alimentación y juego. La mayoría de los niños disminuye además las ecolalias inmediatas y aumenta las iniciaciones comunicativas. Además, tras la práctica simulada, los niños fueron capaces de transferir su conocimiento al ambiente natural del aula en las situaciones trabajadas.

Algunos programas generales de tratamiento incorporan una parte específica para el entrenamiento en los aspectos pragmáticos del lenguaje. Ese es el caso del Programa de «Tratamiento y Educación de niños con Autismo y trastornos Comunicativos relacionados» («Treatment and Education of Autistic and related Communication Handicapped Children»: TEACCH, Watson, 1989). En un principio comenzó a desarrollarse en Carolina del Norte, implicando a los padres, a los alumnos, y a la comunidad. Distingue 5 dimensiones o bloques de contenidos en los actos comunicativos: 1) función, 2) contexto, 3) categoría semántica, 4) estructura y 5) modalidad, que sirven tanto como metodología de enseñanza, como para programar los objetivos comunicativos, que son evaluados de manera inicial (mediante muestras de comunicación espontánea) y de manera continua (con registros y anotaciones). Este programa se basa en un enfoque estructurado de enseñanza basado en la mediación visual y la estructuración del ambiente para estimular la conducta, y tiene como objetivo desarrollar las habilidades comunicativas y su uso espontáneo en contextos naturales. Ofrece un apoyo holístico en las áreas cruciales para la vida independiente (p. ej., habilidades sociales, empleo, etc.), asegurándose de que existe una comunicación y apoyo consistente entre todos los contextos relevantes para el sujeto. Para el colectivo de personas con menor nivel cognitivo está dando muy buenos resultados, pero para las personas con AAF-SA aún no está lo suficientemente desarrollado (García Sánchez, 1999). Este programa es, probablemente, el más completo, coherente y riguroso de todos los existentes en el mundo de la atención a las personas con autismo y sus familias, cubriendo todo el espectro del ciclo vital, coordinando servicios y apoyos que van desde los niveles de educación infantil, primaria, secundaria, vocacional, hasta la vida adulta (García Sánchez, 1999). 
Los resultados del programa TEACCH han sido evaluados, por ejemplo, en función de la satisfacción de los padres sobre la evaluación, diagnóstico, tratamiento y programa escolar (ver Marcus y Schopler, 1989). Por su parte, Mukaddes, Kaynak, Kinali, Besikci e Issever (2004) evaluaron el efecto de 14 sesiones de un programa psicoeducativo derivado del programa TEACCH en su vertiente para la intervención en el hogar (Schopler, Mesibov y Hearsey, 1995). La muestra la componían 10 niños con autismo de entre 24 y 66 meses y 11 con trastorno reactivo ( 9 niños y 2 niñas) de entre 30-70 meses. Aunque los niños con trastorno reactivo mostraron una mejora mayor en el desarrollo global, en las subescalas de nivel de lenguaje y cognitivo, así como en las habilidades de autocuidado, los resultados indican que el enfoque TEACCH es efectivo para ambos grupos.

Unas de las competencias más prototípicamente pragmáticas (por su necesidad de ajuste al interlocutor) lo forman las habilidades de comunicación referencial. Estas habilidades, por ejemplo, la capacidad para adaptar la comunicación a la perspectiva y necesidades del interlocutor, o para autorreestructurar sus mensajes en función de la información que le proporciona su interlocutor, son especialmente deficitarias en este colectivo. Desde el paradigma de comunicación referencial-ecológica, que centra su estudio en los intercambios comunicativos entre una pareja de sujetos con la ayuda de un adulto, se han entrenado habilidades de comunicación con éxito en sujetos con AAFSA (De la Iglesia y Olivar, 2007b).

De la Iglesia (2005) desarrolló un programa de entrenamiento en las habilidades que se consideran fundamentales para comunicar con eficacia (habilidades de comparación de referentes, de cooperación entre participantes y de evaluación de la propia comunicación) basándose en los resultados obtenidos desde este paradigma en la evaluación de dichas habilidades y el potencial de aprendizaje de este colectivo (Olivar y Belinchón, 1997; 1999). La muestra del estudio la formaban 60 parejas de niños y adolescentes, 20 formadas por un emisor con AAF-SA y un receptor con desarrollo normal y 40 en las que ambos miembros tienen desarro- 1lo normal. Los sujetos fueron equiparados en edad cronológica, funcionamiento cognitivo y verbal. Tras una evaluación de las competencias iniciales en la que se muestra una ineficacia comunicativa de los sujetos con AAF-SA, se realiza un programa de entrenamiento en habilidades de comunicación referencial. Los grupos entrenados estaban compuestos por 10 sujetos con AAF-SA y 10 con desarrollo normal, sirviendo el resto de grupos como control de los cambios producidos en la realización de un postest, un transfer cercano y un transfer lejano. Los resultados confirman que los dos grupos entrenados mejoran su realización. Destaca que, tras el periodo de instrucción, el grupo con AAF-SA entrenado asemeja su desempeño al del grupo entrenado con desarrollo normal en la mayoría de las variables seleccionadas como más representativas, en las que inicialmente se mostraba menos competente.

Con la misma metodología de trabajo, De la Iglesia y Olivar (2007c) diseñaron un programa específico de entrenamiento en comunicación referencial. Participaron 20 niños y adolescentes con TEA-AF, distribuidos en dos grupos de 10; uno de los cuales asistió al programa y el otro no. La evaluación de las habilidades de cada uno de los grupos se llevó a cabo antes de la aplicación del programa (pretest), después de terminado éste (postest), y un mes más tarde para comprobar el grado de generalización de lo aprendido. El grupo entrenado mostró una disminución significativa tanto en el postest como en la prueba de generalización en las regulaciones no adaptadas a su interlocutor (intervenciones en las que el hablante intenta aclarar su mensaje, pero lo hace de manera no satisfactoria, sin tener en cuenta lo que necesita su compañero) y un aumento en las auto-reestructuraciones (intervenciones que se mejoran por efecto de la propia planificación del hablante, en las que se pone en práctica la evaluación de la propia comunicación). La capacidad de reestructurar un mensaje de manera adaptada, supone un factor clave para el desarrollo de la eficacia comunicativa. Así, una auto-reestructuración implica la capacidad de detectar la ambigüedad de una intervención, y consecuentemente poner en práctica estrategias comunicativas que procuren resolverla. Dadas las especiales dificultades de este colectivo para generalizar lo apren- 
dido, este dato resulta especialmente interesante de cara a la elaboración de propuestas de actividades para incluir en sus adaptaciones curriculares escolares. Así pues, a pesar de las limitaciones del estudio (número escaso de participantes, limitación de tiempo, grupos clínicos, etc.) el entrenamiento resultó eficaz en la mejora de la competencia sociocomunicativa (capacidad de adoptar la perspectiva del otro y de autoevaluación de la comunicación) en el grupo que había recibido el entrenamiento.

\section{CONCLUSIONES}

Existen pocos estudios controlados y diseñados para la investigación de los entrenamientos en habilidades pragmáticas, comunicativas y sociales con personas con TEA-AF. Sin embargo, la mayoría suelen coincidir en que el aprendizaje de habilidades específicas pueden no generalizarse para proveer de una competencia social en la vida diaria (i.e. Ozonoff y Miller, 1995). Así, aunque existen significativos y numerosos éxitos asociados a los programas de entrenamiento, hemos de considerar que éstos no implican la total adquisición de un comportamiento social flexible y una capacidad de comunicación espontánea y natural (Klin y Volkmar, 2000).

Aunque una parte importante de los programas de intervención tienen como finalidad el fomento de la generalización de las estrategias aprendidas, existe una escasez de estudios empíricos que indiquen tanto la efectividad de estas intervenciones como la generalización de los programas de entrenamiento de las áreas sociales y comunicativas, o las técnicas utilizadas para promover dicha generalización de aprendizajes (Bakken y Bock, 2001; Klin y Volkmar, 2000). Esta situación está cambiando, aceptándose cada vez más la importancia de definir la generalización explícita como uno de los objetivos del entrenamiento, incluyendo estrategias específicas tanto para poder llevarlo a cabo como para evaluar su consecución. Para favorecer esta generalización, tal y como indican Kunce y Mesibov (1998), en los programas de entrenamiento es recomendable utilizar un enfoque estructurado, en que se emplee una instrucción explícita y sistemática.
En conclusión, los trabajos sobre las intervenciones sociocomunicativas en el colectivo de personas con TEA-AF son escasos y en muchas ocasiones se encuentran dentro de programas más amplios de entrenamiento en habilidades sociales. En cuanto a los aspectos metodológicos, se trata de estudios esencialmente cualitativos, pudiendo por ejemplo fundamentar la mejora producida basándose en el criterio del observador o en las opiniones de los familiares, lo que dificulta la tarea de plantear nuevos estudios que los repliquen. Además, en la mayoría resulta difícil identificar de manera inequívoca las características de la muestra (i.e. diagnósticos, criterios de inclusión y exclusión, sexo, edad cronológica y mental, etc.), tanto de los grupos experimentales como los de control; éstos últimos están ausentes en la mayoría de las investigaciones revisadas, lo que dificulta atribuir los cambios exclusivamente a la intervención. Todas estas limitaciones experimentales probablemente vengan fundamentadas, por un lado, por las características propias de la muestra (p. ej., baja prevalencia, falta de acuerdo unánime sobre los criterios diagnósticos para el SA, etc.), y por otro, porque se procura primar la proyección práctica y el interés didáctico de los trabajos realizados (p. ej., diseños de caso único en aulas de centros educativos). La tendencia más actual es a considerar la importancia de la validez empírica de las intervenciones cuyos resultados indican la operatividad de la posterior generalización en el trabajo en el aula.

\section{REFERENCIAS}

Adams, L., Gouvousis, A., Van Lue, M., y Waldron, C. (2004). Social story intervention: Improving communication skills in a child with autism spectrum disorder. Focus on Autism and Other Developmental Disabilities, 19, 87-94.

American Psychiatric Association (2002). DSM-IV-TR. Manual Diagnóstico y Estadístico de los Trastornos Mentales. Texto Revisado. Barcelona: Masson (Original en inglés, 2001).

Arthur, M.R., Rotatori, A.F., y Wahlberg, T. (2001). Counseling techniques for individuals with autistic spectrum disorders. En T. Wahlberg, F. Obiakor, S. Burkhardt y A.F. Rotatori (Eds.), Autistic spectrum disorders: Educational and clinical interventions. Advances in spe- 
cial education (Vol. 14, pp. 235-254). Oxford: Elsevier Science.

Attwood, T. (1998). Asperger's syndrome: A guide for parents and professionals. London: Jessica Kingsley. (Edición en castellano, 2002.).

Attwood, T. (2000). Strategies for improving the social integration of children with Asperger syndrome. Autism, 4, 85-100.

Bakken, J.P., y Bock, S.J. (2001). Developing appropiate curriculum for students with autism spectrum disorders. En T. Wahlberg, F. Obiakor, S. Burkhardt y A. F. Rotatori (Eds.), Autistic spectrum disorders: Educational and clinical interventions. Advances in special education (Vol. 14, pp. 109-132). Oxford: Elsevier Science.

Barry, T.D., Klinger, L., Lee, J.M., Palardy, N., Gilmore, T., y Bodin, S.D. (2003). Examining the effectiveness of an outpatient clinic-based social skills group for High-Functioning children with autism. Journal of Autism and Developmental Disorders, 33, 685-701.

Bledsoe, R., Smith, B., y Simpson, R. L. (2003). Use of a social story intervention to improve mealtime skills of an adolescent with Asperger Syndrome. Autism, 7, 289-295.

Bosseler, A., y Massaro, D.W. (2003). Development and evaluation of a computer-animated tutor for vocabulary and language learning in children with autism. Journal of Autism and Developmental Disorders, 33, 653-672.

Boucher, J. (1999). Interventions with children with autism. Methods based on play. Child Language Teaching and Therapy, 15, 1-5.

Broderick, C., Caswell, R., Gregory, S., Marzolini, S., y Wilson, O. (2002). «Can I join the club?»: A social integration scheme for adolescents with Asperger syndrome. Autism, 6, 427-431.

Carrington, S., y Graham, L. (2001). Perceptions of school by two teenage boys with Asperger syndrome and their mothers: A qualitative study. Autism, 5, 37-48.

Chandler, S., Christie, P., Newson, E.A., y Prevezer, W. (2002). Developing a diagnostic and intervention package for 2-to 3-year-olds with autism: Outcomes of the frameworks for communication approach. Autism, 6, 47-69.

De la Iglesia, M. (2005). Autismo de nivel alto y síndrome de Asperger: Mejora de la competencia comunicativa a través del entrenamiento en comunicación referencial. Tesis Doctoral no publicada. Universidad de Valladolid.

De la Iglesia, M., y Olivar, J. S. (2005). Programas de intervención psicoeducativa para personas con síndrome de Asperger. V Congreso Internacional Virtual de Educación. CIVE 2005 (http//www.cibereduca.com).

De la Iglesia, M., y Olivar, J. S. (2006a). Potenciación de los intereses especiales de personas con síndrome de Asperger mediante actividades de animación sociocultural. VI Congreso Internacional Virtual de Educación. CIVE 2006 (http//www.cibereduca.com).
De la Iglesia, M., y Olivar, J.S. (2006b). Actividades de ocio para personas con dificultades de comunicación y relación social y síndrome de Asperger. VI Congreso Internacional Virtual de Educación. CIVE 2006 (http//www.cibereduca.com).

De la Iglesia, M., y Olivar, J.S. (2007a). Autismo y síndrome de Asperger. Trastornos del espectro autista de alto funcionamiento. Guía para educadores y familiares. Madrid: CEPE.

De la Iglesia, M., y Olivar, J.S. (2007b). Entrenamiento en comunicación referencial ecológica en población con discapacidad. Revista de Psicología General y Aplicada, 60, 119-134.

De la Iglesia, M., y Olivar, J.S. (2007c). Entrenamiento en habilidades sociocomunicativas en los trastornos del espectro autista. Revista de Psicopatología y Psicología Clínica, 12, 33-42.

Delprato, D.J. (2001). Comparisons of discrete-trial and normalized behavioral language intervention for young children with autism. Journal of Autism and Developmental Disorders, 31, 315-325.

Fulk, B.M., y King, K. (2001). Classwide: Peer Tutoring at Work. Teaching Exceptional Children, 34, 49-53.

Gagnon, E. (2001). Power cards: using special interests to motivate children and youth with Asperger syndrome and autism. Kansas: Autism Asperger Publishing.

García Sánchez, J.N. (1999). Normalización y alternativas de intervención psicopedagógica en personas con trastornos del desarrollo. En J.N. García Sánchez (Coor.), Intervención psicopedagógica en los trastornos del desarrollo (pp. 46-64). Madrid: Pirámide.

Glaeser, B.C., Pierson, M.R., y Fritschmann, N. (2003). Comic strip conversations: A positive behavioral. Teaching Exceptional Children, 36, 14-19.

Goldstein, H., Kaczamarek, L., Pennington, R., y Shafer, K. (1992). Peer mediated intervention: Attending to, commenting on, and acknowledging the behavior of preschoolers with autism. Journal of Applied Behavior Analysis, 25, 289-305.

González-Carbajal, A. (2002). Intervención comunicativa en autismo de alto funcionamiento y síndrome de Asperger. En J. Martos, M. Pérez (Eds.), Autismo. Un enfoque orientado a la formación en Logopedia (pp. 85-110). Valencia: Nau Llibres.

González-López, A., y Kamps, D.M. (1997). Social skills training to increase social interactions between children with autism and their typical peers. Focus on Autism and Other Developmental Disabilities, 12, 2-14.

Gray, C. (1998). Social stories and comic strip conversations with students with Asperger syndrome and HighFunctioning Autism. En E. Schopler., G.B. Mesibov y L. J. Kunce (Eds.), Asperger Syndrome or High-Functioning Autism? (pp. 167-198). Nueva York: Plenum Press. 
Gray, C. (2000). The new social story book (Illustrated edition). Arlington (TX): Future Horizons.

Gray, B., Creighton, N., McMahon, M., y Cunningham, D. (1991). Getting started with Bubble Dialogue. Language Development and HyperMedia Research Group Internal Report, University of Ulster at Coleraine, Ulster.

Hadwin, J., Baron-Cohen, S., Howlin, P., y Hill, K. (1996). Can we teach children with autism to understand emotions, belief, or pretence? Development and Psychopathology, 8, 345-365.

Haring, T.G., Breen, C.G., Pitts-Conway, V., Lee, M., y Gaylord-Ross, R. (1987). Adolescent peer tutoring and special friend experiences. Journal for the Association for Persons with Severe Handicaps, 12, 280-286.

Hetzroni, O.E., y Tannous, J. (2004). Effects of a computer-based intervention program on the communicative functions of children with autism. Journal of Autism and Developmental Disorders, 34, 95-113.

Howlin, P. (1998). Children with autism and Asperger syndrome: A guide for practitioners and carers. Chichester: Wiley.

Howlin, P., y Yates, P. (1999). The potential effectiveness of social skills groups for adults with autism. Autism, 3, 299-307.

Jordan, R. (1999). Evaluating practice. Autism, 3, 411- 434.

Jordan, R., y Jones, G.E. (1999). Review of research into educational interventions for children with autism in the UK, Autism, 3, 101-110.

Jordan, R., Jones, G., y Murray, D. (1998). Educational interventions for children with autism: A literature review of recent and current research. Sudbury: Department of education and employment.

Kamps, D.M., Leonard, R., Vernon, S., Dugan, E.P., y Delquadri, J.C. (1992). Teaching social skills to students with autism to increase peer interactions in an integrated first-grade classroom. Journal of Applied Behavior Analysis, 25, 281-288.

Kamps, D.M., Royer, J., Dugan, E., Kravits, T., GonzálezLópez, A., García, J., Carnazzo, K., Morrison, L., y Kane, L.G. (2002). Peer training to facilitate social interaction for elementary students with autism and their peers. Exceptional Children, 68, 173-187.

Klin, A., y Volkmar, F.R. (2000). Treatment and intervention guidelines for individuals with Asperger syndrome. En A. Klin, F.R. Volkmar, y S.S. Sparrow (Eds.), Asperger syndrome. (pp. 340-366). Nueva York: Guilford Press.

Koegel, L.K. (2000). Interventions to facilitate communication in autism. Journal of Autism and Developmental Disorders, 30, 383-391.

Koegel, L.K., Camarata, S., Valdez-Menchaca, M.C., y Koegel, R.L. (1998). Setting generalization of question-asking by children with autism. American Journal on Mental Retardation, 102, 346-357.
Koegel, L.K., Koegel, R.L., Shoshan, Y., y McNerney, E. (1999). Pivotal Response Intervention II: Preliminary long-term outcome data. Journal of the Association for Persons with Severe Handicaps, 24, 186-198.

Koegel, R.L., y Koegel, L.K. (1995). Teaching children with autism: Strategies for initiating positive interactions and improving learning opportunities. Baltimore: Brookes.

Koning, C., y Magill-Evans, J. (2001). Social and language skills in adolescent boys with Asperger syndrome. Autism, 5, 23-36.

Kunce, L., y Mesibov, G.B. (1998). Educational approaches to High-Functioning Autism and Asperger syndrome. En E. Schopler, G.B. Mesibov y L.J. Kunce (Eds.), Asperger Syndrome or High-Functioning Autism? (pp. 227-262). Nueva York: Plenum Press.

Kuttler, S., Myles, B.S., y Carlson, J.K. (1998). The use of social stories to reduce precursors to tantrum behavior in a student with autism. Focus on Autism and Other Developmental Disabilities, 13, 176-182.

Laushey, K.M., y Heflin, L.J. (2000). Enhancing social skills of kindergarten children with autism through the training of multiple peers as tutors. Journal of Autism and Developmental Disorders, 30, 183-193.

Lovaas, O.I., Smith, T., y McEachin, J.J. (1989). Clarifying comments on the young autism study: Reply to Schopler, Short y Mesibov. Journal of Consulting and Clinical Psychology, 57, 165-167.

Luiselli, J.K., Taras, M., y Lennon, L. (1998). Behavioral support for persons with Asperger disorder. Mental Health Aspects of Developmental Disabilities, 1, 1-9.

Macleod, A. (1999). The Birmingham community support scheme for adults with Asperger syndrome. Autism, 3, 177-192.

Marcus, L.M., y Schopler, E. (1989). Parents as co-therapists with autistic children. En C.E. Schaefer y J. M. Briesmeister (Eds.), Handbook of parent training (pp. 337-360). Nueva York: John Wiley \& Sons.

Marriage, K.J., Gordon, V., y Brand, L. (1995). A social skills group for boys with Asperger's syndrome. Australian and New Zealand Journal of Psychiatry, 29, 58-62.

Martín Borreguero, P. (2004). El síndrome de Asperger: ¿Excentricidad o discapacidad social?. Madrid: Alianza.

Mukaddes, N.M., Kaynak, F.N., Kinali, G., Besikci, H. e Issever, H. (2004). Psychoeducational treatment of children with autism and reactive attachment disorder. Autism, 8, 101-109.

Olivar, J.S. (2002). Investigación en trastornos de la comunicación y relación social. En C. Maganto (Dir.) Investigaciones en Psicología clínica (pp. 257-284). San Sebastián: Ibaeta Psicología.

Olivar, J.S., y Belinchón, M. (1997). Ineficacia en la comunicación referencial de personas con autismo y 
otros trastornos relacionados: Un estudio empírico. Anuario de Psicología, 75, 119-145.

Olivar, J.S., y Belinchón, M. (1999). Comunicación y trastornos del desarrollo. Valladolid: Servicio de Publicaciones de la Universidad de Valladolid.

Olivar, J.S., y De la Iglesia, M. (2007). Intervención psicoeducativa en personas con autismo y síndrome de Asperger. Manual práctico. Madrid: CEPE.

Ozonoff, S., Dawson, G., y McPartland, J. (2002). A parent's guide to Asperger syndrome and High-Functioning Autism. Nueva York: Guilford Press.

Ozonoff, S., y Miller, J.N. (1995). Teaching theory of mind: A new approach to social skills training for individuals with autism. Journal of Autism and Developmental Disorders, 25, 415-433.

Rajendran, G., y Mitchell, P. (2000). Computer mediated interaction in Asperger's syndrome: The Bubble Dialogue program. Computers and Education, 35, 189-207

Rivière, A. (1997). Tratamiento y definición del espectro autista II: Anticipación, flexibilidad y capacidades simbólicas. En A. Rivière y J. Martos (Comps.), El tratamiento del autismo: Nuevas perspectivas (pp. 107160). Madrid: Imserso.

Rogers, M.F., y Myles, B.S. (2001). Using social stories and comic strip conversations to interpret social situations for an adolescent with Asperger Syndrome. Intervention in School and Clinic, 36, 310-313.

Rogers, S.J. (2000). Interventions that facilitate socialization in children with autism. Journal of Autism and Developmental Disorders, 30, 399-413.

Rowe, C. (1999). Do social stories benefit children with autism in mainstream primary schools? British Journal of Special Education, 26, 12-15.

Sainato, D.M., Goldstein, H., y Strain, P.S. (1992). Effects of self-evaluation on preschool children's use of social interaction strategies with their classmates with autism. Journal of Applied Behavior Analysis, $25,127-141$.

Salt, J., Sellars, V., Shemilt, J.C., Boyd, S., Coulsdon, T., y McCool, S. (2001). The Scottish Centre for Autism preschool treatment programme: I: A developmental approach to early intervention. Autism, 5, 362-373.

Salt, J., Shemilt, J.C., Sellars, V., Boyd, S., Coulsdon, T., y McCool, S. (2002). The Scottish Centre for Autism preschool treatment programme. II: The results of a controlled treatment outcome study. Autism, 6, 33-46.

Savner, J.L., y Smith, B. (2000). Making Visual Supports. Work in the Home and Community. Kansas: Autism Asperger Publishing Co.

Schopler, E., y Mesibov, G.B. (1992). High-Functioning individuals with autism. Nueva York: Plenum Press.
Schopler, E., Mesibov, G.B., y Hearsey, K. (1995). Structured teaching in the Teacch system. En E. Schopler y G.B. Mesibov (Eds.), Learning and cognition in autism (pp. 243-268). Nueva York: Plenum.

Schopler, E., Mesibov, G.B., y Kunce L.J. (1998). Asperger syndrome or High-Functioning Autism? (pp. 385399). Nueva York: Plenum.

Simpson, R.L. (2004). Finding effective intervention and personnel preparation practices for students with autism spectrum disorders. Exceptional Children, 70, 135-144.

Stoddart, K. (1999). Adolescents with Asperger syndrome: Three case studies of individual and family therapy. Autism, 3, 255-271.

Sussman, F. (1999). More Than Words: Helping Parents Promote Communication and Social Skills in Children with Autism Spectrum Disorder. Canadá: Hanen.

Swaggart, B.L., Gagnon, E., Bock, S.J., Earles, E.L., Quinn, C., Myles, B.S., y Simpson, R.L. (1995). Using social stories to teach social and behavioral skills to children with autism. Focus on Autistic Behavior, 10, 1-15.

Tamarit, J., De Dios, J., Domínguez, S., y Escribano, L. (1990). PEANA: Proyecto de Estructuración Ambiental en el aula de niños autistas. Memoria final del proyecto subvencionado por la Consejería de Educación de la Comunidad de Madrid y la Dirección General de Renovación Pedagógica del MEC.

Ventoso, M.R., y Osorio, I. (1997). El empleo de materiales analógicos como organizadores del sentido en personas autistas. En A. Rivière y J. Martos (Comps.), El tratamiento del autismo: Nuevas perspectivas (pp. 565-588). Madrid: Imserso.

Watson, L. (1989). TEACCH. Teaching spontaneous communication to autistic and developmentally handicapped children. Nueva York. Irvington.

Webb, B.J., Miller, S.P., Pierce, T.B., Strawser, S., y Jones, W.P. (2004). Effects of social skill instruction for highfunctioning adolescents with autism spectrum disorders. Focus on Autism and Other Developmental Disabilities, 19, 53-62.

Wellman, H., Baron-Cohen, S., Caswell, R., Gómez, J. C., Swettenham, J., Toye, E., y Lagattuta, K. (2002). Thought-bubbles help children with autism acquire an alternative to a theory of mind. Autism, 6, 343-363.

Winterman, K.G., y Sapona, R.H. (2002). Everyone's included: Supporting young children with autism spectrum disorders in a responsive classroom learning environment. Teaching Exceptional Children, 35, 30-35.

Zercher, C., Hunt, P., Schuler, A., y Webster, J. (2001). Increasing joint attention, play and language through peer supported play. Autism, 5, 374-398. 